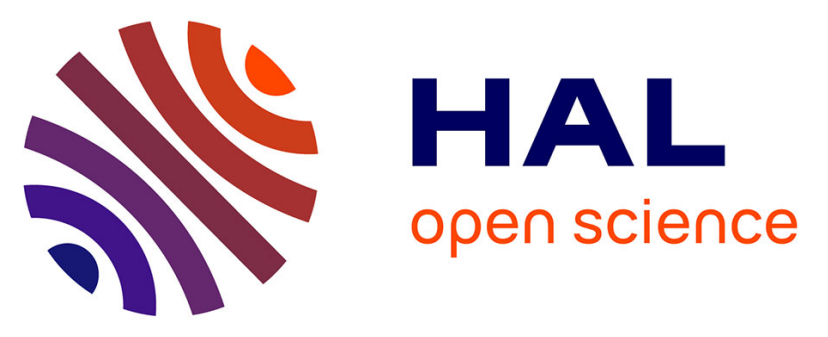

\title{
Developing a passive acoustic monitoring technique for Australia's most numerous seabird, the Short-tailed Shearwater (Ardenna tenuirostris)
}

Katherine C Brownlie, Ross Monash, Johanna J Geeson, Jérôme Fort, Paco Bustamante, John P.Y. Arnould

\section{To cite this version:}

Katherine C Brownlie, Ross Monash, Johanna J Geeson, Jérôme Fort, Paco Bustamante, et al.. Developing a passive acoustic monitoring technique for Australia's most numerous seabird, the Short-tailed Shearwater (Ardenna tenuirostris). Emu, 2020, 120 (2), pp.123-134. 10.1080/01584197.2020.1732828. hal-02994244

\section{HAL Id: hal-02994244 \\ https://hal.science/hal-02994244}

Submitted on 7 Nov 2020

HAL is a multi-disciplinary open access archive for the deposit and dissemination of scientific research documents, whether they are published or not. The documents may come from teaching and research institutions in France or abroad, or from public or private research centers.
L'archive ouverte pluridisciplinaire HAL, est destinée au dépôt et à la diffusion de documents scientifiques de niveau recherche, publiés ou non, émanant des établissements d'enseignement et de recherche français ou étrangers, des laboratoires publics ou privés. 
Developing a passive acoustic monitoring technique for Australia's most numerous seabird, the Short-tailed Shearwater (Ardenna tenuirostris)

\author{
Katherine C. Brownlie ${ }^{\mathrm{a}, \mathrm{b}}$, Ross Monash ${ }^{\mathrm{c}}$, Johanna J. Geeson ${ }^{\mathrm{a}}$, Jérôme Fort ${ }^{\mathrm{b}}$, Paco Bustamante ${ }^{\mathrm{b}, \mathrm{d}}$ \\ and John P. Y. Arnould ${ }^{\mathrm{a}}$ \\ ${ }^{a}$ School of Life and Environmental Sciences, Deakin University, Burwood, Australia \\ ${ }^{\mathrm{b}}$ Littoral Environnement et Sociétés, UMR 7266 CNRS, La Rochelle Université, La Rochelle, \\ France \\ ${ }^{\mathrm{c}}$ Department of Primary Industries, Parks, Water and Environment, Hobart, Australia

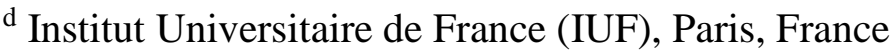

\begin{abstract}
Establishing appropriate conservation management objectives and actions for seabirds requires timely detection of changes in their populations. However, obtaining regular accurate measures of seabird population size and trends can be difficult due to logistical and financial constraints in accessing remote breeding sites. The Short-tailed Shearwater (Ardenna tenuirostris) is a wideranging, burrow-nesting Procellariiform with an estimated breeding population size of ca 23 million individuals. Despite its ecological significance, there is currently limited monitoring of the species. In the present study, eight acoustic data loggers were deployed across six sites over two breeding seasons to assess the efficacy of acoustic monitoring. Five acoustic indices were used to investigate vocal activity over the breeding season, detect phenology events, and to determine the most accurate period to assess the density of occupied nests. The general pattern over the breeding season was similar for several of the acoustic indices and reflected colony attendance patterns. Linear regressions fitted to the normalised difference soundscape index values and density of occupied nests (burrows $\cdot \mathrm{m}^{-2}$ ) revealed significant relationships in both the incubation and chickrearing. The results suggest that passive acoustic monitoring could be used as an effective method to predict nesting density in Short-tailed Shearwater breeding colonies. Used in conjunction with information on the breeding colony area, this could enable regular estimates of colony population size. Such information is crucial for the early detection of population trajectory changes. The method may also be applicable for other burrow- or surface-nesting seabirds for which regular wide-spread monitoring currently proves difficult.
\end{abstract}

Keywords: Bioacoustics; monitoring; Ardenna tenuirostris; burrownesting; seabird; acoustic; indices; Short-tailed Shearwater 


\section{Introduction}

Nearly half of the world's seabird species are currently experiencing population declines (Croxall et al. 2012). Correspondingly, establishing appropriate conservation management objectives and actions for seabirds is urgently needed. Obtaining regular accurate measures of population distribution and size, to enable the timely detection of changes in their population trends (Buxton et al. 2016b), is crucial for such endeavours (Croxall et al. 2012). However, many seabird species have wide breeding distributions and often nest on remote, hard to access islands (Schreiber and Burger 2002) presenting logistical and financial constraints for direct survey counts and markrecapture estimates (Parker and Rexer-Huber 2016). While recent advances in satellite imagery and unmanned aerial vehicles have enabled more cost-effective censuses of colonies in remote locations (Brisson-Curadeau et al. 2017; Fretwell et al. 2017), these techniques have limited effectiveness for burrow-nesting species, which includes many of the wide-ranging pelagic species that are experiencing the largest seabird population declines (Croxall et al. 2012).

The Short-tailed Shearwater (Ardenna tenuirostris) is a medium-sized (average mass $580 \mathrm{~g}$ ), wideranging, burrow-nesting Procellariiform that breeds only in southern Australia (Marchant and Higgins 1990). Considered to be Australia's most numerous seabird, the most recent total population estimate is 23 million individuals breeding in approximately 285 colonies (Skira et al. 1996). During the breeding season, extending from September to April, an estimated 661,000 tons of marine biomass is consumed by Short-tailed Shearwaters in Bass Strait, south-eastern Australia (Schumann 2012). In addition, they play an important role in terrestrial environments as both nutrient transporters and ecosystem engineers (Otero et al. 2018). With their trans-equatorial migration extending from the Antarctic to the Arctic, the annual life cycle of the Short-tailed Shearwater covers an extensive geographical range. As a result, they exploit habitats with widely different environmental conditions and differing levels of environmental variability. Its breeding range in south-eastern Australia is currently one of the fastest warming oceanic regions in the Southern Hemisphere (Cai et al. 2005; Lough and Hobday 2011), with changes in species distribution and abundance already occurring across multiple taxa (Last et al. 2011; Wernberg et al. 2011). Furthermore, rapid climate-driven changes are occurring within the foraging range of the Short-tailed Shearwater in Arctic and Antarctic regions (Comiso et al. 2008; Schofield et al. 2010),

resulting in variation in prey species phenology (Yamamoto et al. 2014), altered community structure and distribution shifts (Gall et al. 2017). 
The predicted changes in the marine environment are likely to influence prey density and availability, and potential decreases in prey populations may ultimately result in lowered breeding success or increased susceptibility to mortality for Short-tailed Shearwaters (Baduini et al. 2001a). Indeed, several studies have already noted a decreasing trend in the Short-tailed Shearwater population, with an estimated reduction of $35 \%$ in parts of their range over recent decades (Vertigan 2010; Schumann et al. 2014). In view of their ecological significance (both in south-eastern Australia and throughout their annual distribution), understanding the factors that influence the species' population dynamics is crucial for predicting how it may respond to anticipated environmental changes. Fundamental to this endeavour is obtaining regular estimates of population size and breeding success (Precheur et al. 2016). Consequently, there is a pressing need for new cost-effective methodologies for regularly monitoring Short-tailed Shearwater breeding colonies. Acoustic monitoring provides a promising method for surveying wildlife populations, particularly where direct counts, mark-recapture or visual surveys are not logistically possible or economically feasible (Marques et al. 2013). Acoustic data can be collected continuously for extended periods and simultaneously across multiple sites with minimal disturbance to study populations (Buxton et al. 2018). Over the past decade, autonomous acoustic data loggers have been used in several seabird population studies, offering an alternative to physical surveys for both burrow- and surface-nesting species (Buxton and Jones 2012; Borker et al. 2014; Oppel et al. 2014; Arneill et al. 2019). However, few studies have been performed on large, densely populated breeding colonies limiting the method's wider applicability. Given the challenges associated with monitoring burrow-nesting species (some show nocturnal behaviour, breed in cryptic burrows or at remote breeding sites; Schumann et al. 2013b), acoustic data loggers show potential as a reliable long-term population monitoring tool for burrow-nesting seabird colonies (Oppel et al. 2014) that should be further developed.

Through the collection of passive acoustic data, the aims of the present study were to: 1) examine the nightly temporal variation in vocal activity and variation over the reproductive season in relation to phenology and 2) derive a predictive relationship for nest-burrow density and vocal activity in Short-tailed Shearwaters. 


\section{Methods}

\section{Field sites and data collection}

Eight autonomous acoustic data loggers (SongMeter SM4, Wildlife Acoustics Inc., Concord, MA) were deployed within Short-tailed Shearwater breeding colonies at six sites across south-eastern Australia (Figure S1) from September-October to March-April over two breeding seasons (2016/17 and 2017/18). The sites were selected to provide a range of different nest-burrow densities and to encompass a relatively large part of the Short-tailed Shearwater breeding range. Loggers were attached with cable ties to a metal stake approximately $50 \mathrm{~cm}$ above the ground within a site representative of the wider area (nest density and vegetation type). As breeding shearwaters are primarily vocally active at night, each data logger was programmed to record (WAV format) $1 \mathrm{~min}$ every 10 min from $1 \mathrm{~h}$ before local sunset to $1 \mathrm{~h}$ after local sunrise. Gain on both the left and right microphones was set to the manufacturer default of $16 \mathrm{~dB}$, with a high-pass filter of $220 \mathrm{~Hz}$ and a sample rate of $32 \mathrm{kHz}$ in stereo.

In each breeding season, nest-burrow censuses were conducted to assess nest occupancy during the beginning of the incubation period (December 6-17 and 7-18 in 2016 and 2017, respectively) and mid- to late-chickrearing (March 1-11 and 8-29 in 2017 and 2018, respectively). All nest-burrows within a $10 \mathrm{~m}$ radius of the acoustic data loggers were examined during daylight hours for the presence of Short-tailed Shearwater adults (December and March) or chicks (March). While Song Metres have been reported to detect vocalisations up to $50 \mathrm{~m}$ away (e.g. Buxton and Jones 2012; Oppel et al. 2014), censuses of areas with radii around the loggers to such a distance (total search area $7854 \mathrm{~m}^{2}$ ) were not logistically feasible (even in breeding colonies with medium densities of nest-burrows e.g. 0.5 burrows $\cdot \mathrm{m}^{-2}$ ). Correspondingly, to maintain consistency between sites with lower and higher densities of nest-burrows, a census radius of $10 \mathrm{~m}$ was used around loggers placed in areas of contiguous habitat. It was assumed that nest-burrow density was consistent within these areas (Schumann et al. 2013b).

Nest censuses were conducted through the use of a burrowscope (Sextant Technology Ltd), manual inspection by hand (for shallow burrows), and/or by feeling for an occupant with a flexible probe. This last method, hereafter referred to as grubbing (Parker and Rexer-Huber 2016), involved reaching into the burrow with a flexible probe to feel for or detect movement by an occupant. Burrows were either classified as occupied, unoccupied or unknown when burrows were either too 
deep or structurally difficult to determine occupancy. At several sites Little Penguins (Eudyptula minor) are known to breed and occupy burrows within the Shorttailed Shearwater breeding colonies. Burrows were distinguished between the two species through the presence of birds, egg/s, feathers, faecal matter or odour, vocalisations, and by burrow dimensions (shape, entrance diameter, depth; Schumann et al. 2013b).

Due to the nature of the different breeding colonies (soil type, vegetation, burrow structure and depth) and logistical constraints, different techniques were used when undertaking the nest censuses including manual inspection, burrowscope and the grubbing method. Manual inspection (for shallow burrows) and burrowscope provide the most reliable and consistent methods for determining nest-burrow occupancy while the grubbing method with the probe can often lead to a greater number of unknowns or false negative errors when burrows are complex or deep (Parker and Rexer-Huber 2016). Consequently, to assess this potential source of error, the occupied burrow status for the burrowscope and grubbing methods were compared for eight nest censuses on Gabo Island.

\section{Data processing and analyses}

Due to the volume of data collected from the long-term deployments at multiple sites, acoustic recordings could not be manually analysed. Initial trials were conducted to quantify vocal activity through detecting the number of individual vocalisations in each acoustic recording using automated software call recognition and clustering techniques. However, due to the high volume of overlapping Short-tailed Shearwater vocalisations in acoustic recordings at the majority of the breeding colonies, this method proved unreliable. The potential limitations of call detection algorithms to count individual vocalisations at densely populated seabird colonies have previously been noted by Buxton and Jones (2012) and Borker et al. (2014).

An alternative approach to rapidly extract meaningful information from acoustic recordings is the use of acoustic indices (Towsey et al. 2014; Buxton et al. 2016a; Borker et al. 2020). Acoustic indices provide mathematical summaries of the distribution of acoustic energy within a recording (Towsey et al. 2014; Buxton et al. 2018), and are increasingly being used in ecological applications. In the present study, five acoustic indices were investigated for their applicability as a method to analyse this acoustic dataset: normalised difference soundscape index (NDSI), acoustic complexity 
index (ACI); acoustic diversity index (ADI); acoustic evenness index (AEI); and bioacoustic index (BIO). The acoustic indices will be hereafter referred to using these abbreviations, consistent with other papers that have used these indices (e.g. Fuller et al. 2015).

Sounds occurring within a landscape can be humangenerated (anthrophony), produced by living organisms (biophony) or created by geophysical processes such as wind or water flow (geophony; Pijanowski et al. 2011). Biological sounds, including seabird vocalisations, are most prevalent between $2000-8000 \mathrm{~Hz}$ (Kasten et al. 2012). It was assumed that the acoustic indices would reflect variation in Short-tailed Shearwater vocalisations as they were the predominant source of biophony across the study sites. Although Little Penguins were breeding at several of the sites, their breeding population numbers and vocalisations were considerably lower than Short-tailed Shearwaters.

The NDSI was developed to estimate the relative amount of anthropogenic and biological components in an acoustic recording, and is calculated by computing the ratio (range of -1 to +1 ) of anthrophony to biophony (Kasten et al. 2012). While few anthropogenic sounds were expected to be detected at the remote monitoring sites, many sounds within the geophony can occur within the same frequency range as the anthrophony range (e.g. wind or rain). At these study sites it is likely that the NDSI is reflecting the ratio of geophony to biophony in the soundscape rather than anthrophony to biophony. However, to maintain consistency with previous studies and the packages used for data analysis, the NDSI will still be referred to as the ratio of anthrophony to biophony.

The ACI is based on the observation that biotic sounds are characterised by an intrinsic variability of intensities, while anthropogenic noise is generally constant in intensity. It is calculated as the average absolute fractional change in spectral amplitude from one spectrum to the next, averaged over all frequency bins for the entire recording (Pieretti et al. 2011; Towsey et al. 2014). The ADI and AEI are both calculated by dividing the spectrogram into bins (frequency bands) and taking the proportion of the signals in each bin above a threshold, and applying the Shannon index (ADI) or Gini coefficient (AEI) to these bins (Villanueva-Rivera et al. 2011; Villanueva-Rivera and Pijanowski 2016). The Shannon index (Shannon and Weaver 1949) is widely used in ecology as a measure of species diversity, while the Gini index (Gini 1912) is used to estimate species evenness. The BIO index, developed by Boelman et al. (2007), is a function of both the signal intensity and number of frequency bands within an acoustic recording. This index is calculated as the area under 
each curve for all frequency bands associated with the $\mathrm{dB}$ value that was greater than the minimum dB value for each curve (Villanueva-Rivera and Pijanowski 2016).

For each of the acoustic data logger deployments, the five acoustic indices were computed from the 1 min acoustic recordings using default package parameters in the soundecology (VillanuevaRivera and Pijanowski 2016) and tuneR packages (Ligges et al. 2018) within the R statistical environment (R Core Team 2019). The NDSI ratio of (biophony - anthrophony)/(biophony + anthrophony) was computed with the frequency interval corresponding to the anthrophony at 1000$2000 \mathrm{~Hz}$ and the biophony at $2000-11,000 \mathrm{~Hz}$. The ACI was calculated across the whole frequency range $(0-32,000 \mathrm{~Hz}$ ) with $\mathrm{j}$ (the cluster size in seconds) set to 5 and the fft_w (Fast Fourier Transform window size) set to the default 512. The ADI and AEI were calculated using frequency steps of 1000 and a threshold of $-50 \mathrm{~dB}$ across the frequency range $0-10,000 \mathrm{~Hz}$, while the BIO was calculated using the frequency range $2000-8000 \mathrm{~Hz}$ and the fft_w set at 512 . The acoustic index values for the left and right microphone channels were then averaged to provide a single value for each sampling interval.

To investigate the nightly temporal variability in the acoustic indices, hourly trends were examined over the whole breeding season for each site. Curves were fitted to the hourly values with Generalised Additive Models (GAMs) using the mgcv package (Wood 2004). Inspection of these plots was conducted to select the most appropriate period to compare across the breeding season and between indices. The values over this period were then averaged to provide a daily value for each acoustic index. The daily acoustic index values over the breeding season were then examined to assess the ability to detect phenology events and to determine the most appropriate periods to relate them to the density of occupied nest-burrows.

Several studies have documented the effect of moonlight on colony attendance behaviour and vocal activity in seabirds. For example, Scopoli's Shearwaters (Calonectris diomedea) have been shown to avoid moonlight when attending breeding colonies, with $80 \%$ of burrow entrances by birds occurring in the absence of moonlight (Rubolini et al. 2015). In addition, vocal activity has been shown to be significantly lower when the moon is visible and decreases with increasing lunar phase in multiple petrel species (Mougeot and Bretagnolle 2000). Correspondingly, following initial inspection of the daily acoustic indices throughout the breeding season, values for the night of the new moon and two nights either side of this date (to account for potential variation due to weather conditions) were averaged to obtain a mean new moon value for December (incubation) and March 
(late chick-rearing) at each site. The incubation and chick-rearing periods were analysed separately within the R statistical environment (R Core Team 2019) and simple linear regressions were fitted to the new moon acoustic index values with the density of occupied nest-burrows as the dependent variable. For comparison, similar regressions were generated using the daily acoustic index values on the respective dates of the nest censuses.

\section{Results}

A total of 104,299 and 121,433 minutes of acoustic recordings were obtained over the 2016/17 and 2017/ 18 breeding seasons, respectively. Due to device malfunctions, not all acoustic data loggers recorded for entire breeding seasons (Table S1). Over the whole breeding season, the nightly temporal variation in the acoustic indices predicted from GAMs displayed similar patterns, though at different absolute values, across the various sampling sites (Figure 1). The NDSI, ACI and ADI all displayed the greatest values in the hours before sunrise while the AEI showed a similar, but inverse, pattern. In contrast, the BIO had higher values before sunset for the Kanowna sites and showed an overall increase throughout the night for Fort Direction and Gabo Island. The hours prior to sunrise corresponded to the period when many birds begin to exit their burrows and are highly vocal both within their burrows and on the surface, with few individuals flying around the colony at this time. Therefore, the acoustic index values in the two hours to one hour prior to sunrise each night were averaged to provide the mean daily acoustic index value for comparison between indices and across the breeding season.

The mean daily acoustic index values for NDSI, ACI, and ADI followed the same general pattern, albeit with different amplitudes, over the entire breeding season (Figure 2). Values increased in late September until mid-October and then sharply decreased in early-mid November, corresponding to the pre-laying exodus of birds to the Southern Ocean before rising again in late November, coinciding with the return of birds to the colonies and the start of the incubation period (Serventy 1967). While there was some variability, values remained high until the beginning of March before generally decreasing until mid-late April when data logging ceased. The AEI showed a general inverse pattern, most closely mirroring the ADI, over the breeding season. While there were substantial periodic peaks, coinciding with those observed in the other indices, the general pattern of BIO values was more constant than in the other indices. 
To account for the different nest census methods, a conversion factor was determined from the differences between the occupied burrow status using the burrowscope and grubbing methods for eight nest censuses conducted on Gabo Island in 2016/2017 and 2017/18 (Table S2). This conversion factor was calculated by dividing the number of occupied nest-burrows using the burrowscope method with the number of occupied nest-burrows for the grubbing method and taking the average for all December or March nest censuses. Where the grubbing method was used, the number of occupied nest-burrows was multiplied by a conversion factor of 1.33 and 1.23 in December and March, respectively. The density of nest-burrows within a $10 \mathrm{~m}$ radius of the acoustic data loggers (including occupied, unoccupied and unknown status burrows) varied across the sites, ranging from 0.01 to 1.20 burrows $\cdot \mathrm{m}^{-2}$ at Point Danger and Kanowna Island Site 1, respectively (Table 1). It varied during the incubation period censuses (December), ranging between $0-0.66$ burrows $\cdot \mathrm{m}^{-2}$ and $0-0.70$ burrows $\cdot \mathrm{m}^{-2}$ in 2016 and 2017. During the chickrearing period censuses (March) the density of occupied nest-burrows was between $0-0.24$ burrows $\cdot \mathrm{m}^{-2}$ and $0-0.46$ burrows $\cdot \mathrm{m}^{-2}$ in 2017 and 2018 , respectively.

The linear relationships between the mean new moon acoustic index values and the density of occupied nest-burrows at the census dates during the incubation $(\mathrm{n}=14)$ and chick-rearing $(\mathrm{n}=$ 10) periods varied between the acoustic indices (Table 2). The NDSI showed a positive linear relationship with occupied nest density (burrows $\left.\cdot \mathrm{m}^{-2}\right)$ significant for both the incubation $(\mathrm{F} 1,12=$ 18.21, $\left.\mathrm{P}<0.001, \mathrm{r}^{2}=0.60\right)$ and chick-rearing periods $\left(\mathrm{F} 1,8=63.73, \mathrm{P}<0.001, \mathrm{r}^{2}=0.89\right.$, Figure 3). A significant regression was observed between the ACI and occupied nest density (burrows $\left.\cdot \mathrm{m}^{-2}\right)$ for the incubation period $\left(\mathrm{F} 1,12=21.45, \mathrm{P}=0.001, \mathrm{r}^{2}=0.64\right)$, and for the ADI in the chick-rearing $\left(\mathrm{F} 1,8=5.47, \mathrm{P}=0.048, \mathrm{r}^{2}=0.41\right)$. No significant relationships were observed for the indices AEI or BIO. Additionally, the relationship between the mean census date acoustic index values and density of occupied nest-burrows was investigated and significant results were observed for the NDSI during both the incubation $\left(\mathrm{F} 1,12=20.27, \mathrm{P}=0.001, \mathrm{r}^{2}=0.63\right)$ and chickrearing periods $\left(\mathrm{F} 1,12=11.36, \mathrm{P}=0.010, \mathrm{r}^{2}=0.59\right.$, Table $\left.\mathrm{S} 3\right)$.

Given the significant linear relationship between the NDSI and occupied nest density during both the incubation and chick-rearing, the NDSI was used to further examine variation in vocal activity in relation to phenology between sites across the breeding range and years over the breeding season. In 2016/17, while NDSI values at Kanowna Island Site 1, Whalebone Point and Gabo Island Site 2 followed a common general pattern, several differences between the sites were observed (Figure 
S2). The NDSI values increased earlier at Kanowna Island Site 1 than at Whalebone Point, showing that the Short-tailed Shearwaters started returning from their winter migration $5 \mathrm{~d}$ earlier at the former site. The pre-laying exodus period in November, with low NDSI values, was $4 \mathrm{~d}$ longer for Gabo Island Site 2. In 2017/18, the NDSI values for Kanowna Island Site 2 increased later, suggesting that the Short-tailed Shearwaters returned 7 d later, than in 2016/2017. The low NDSI values in November indicate that the prelaying exodus was slightly longer (by 1-2 d) and later (by 1-2 d) for both Kanowna Island Site 1 and Gabo Island Site 2 in 2017/18 than 2016/17. A longer prelaying exodus was also observed in 2017/18 for the Tasmanian site Cloudy Bay (17 d) than the closely located Whalebone Point (11 d) in 2016/17.

\section{Discussion}

Trialled at various locations across the species' breeding range in colonies of varying size and nest density, the present study provides further insights on the use of passive acoustics to monitor seabird populations. The results indicate that passive acoustic monitoring can be used as an effective method to predict nesting density in Short-tailed Shearwater breeding colonies. In addition, it can be used to gain valuable basic information on breeding phenology including the timing of arrival at breeding colonies and duration of the pre-laying exodus.

The acoustic indices provided a means for analysing vocal activity in medium to densely populated seabird colonies, overcoming the limitations posed by abundant overlapping calls. Overall, the NDSI provided the strongest relationship between vocal activity and density of occupied nestburrows.

\section{Acoustic indices}

In the present study the high number of overlapping calls by individuals, even in colonies considered to be of medium breeding density, rendered automated call recognition models unreliable, confirming such limitations highlighted in previous studies (see Buxton and Jones 2012; Borker et al. 2014). Consequently, acoustic indices were investigated as a method to quantify vocal activity at the Short-tailed Shearwater study colonies. The nightly temporal variation showed differences and similarities between the various acoustic indices analysed. Although the NDSI was 
developed to determine the relative amount of anthropogenic and biological components in the soundscape (Kasten et al. 2012), its application in the present study was at remote sites with minimal anthropogenic sounds. Sounds occurring at the breeding colonies within the anthrophony range of 1000-2000 Hz also included the geophony (e.g. rain and wind), other bird species and Australian Fur Seals (Arctocephalus pusillus doriferus) present in the vicinity of some study locations. The geophony can cover the entire spectrum but is strongest at the lower frequencies (Sueur et al. 2014). Short-tailed Shearwater vocalisations occur primarily within frequency bands in the biophony range. Correspondingly, as the NDSI generally equates to a ratio between biophony and geophony, the nightly temporal variation in the NDSI values over the night reflects the relative increase or decrease in Short-tailed Shearwater vocal activity.

The ACI has been shown to be strongly correlated with bird vocalisations, due to the capacity of the index to highlight rapid variations of intensity in each single frequency bin. Sounds with constant levels of intensity such as insect sounds, anthropogenic noise or some of those occurring within the geophony give low ACI values (Pieretti et al. 2011). In the present study, the variation in ACI values observed throughout the night likely reflects the nightly variation in Short-tailed Shearwater vocalisations. For the ADI, higher values reflect greater acoustic diversity, whereas for the AEI, values closer to zero reflect greater evenness in a recording with sounds occurring equally across the frequency bands (Villanueva-Rivera et al. 2011). These two indices indicate that there is high acoustic diversity during the night, with sounds occurring across a range of frequencies between 0-10,000 Hz. Like the ACI, the BIO index is calculated based on the change in signal intensity and reflects the intensity of sound in the landscape (Fuller et al. 2015), though the BIO index is calculated using the biophony range only. The nightly temporal variation in the BIO suggests that this acoustic index may be more sensitive to the diurnal biophony, with the highest values observed prior to sunset and around or after sunrise.

Acoustic monitoring studies are generally designed to ensure acoustic recordings cover the period of peak vocal activity for seabird species (e.g. Buxton and Jones 2012). In the present study, the common nightly pattern shared by the NDSI, ACI, ADI and AEI indicates a peak vocal activity for Short-tailed Shearwaters occurring in the hours before sunrise, which is consistent with observations made in the field (Gabo and Kanowna Islands) and for other seabird species (Buxton and Jones 2012; Cragg et al. 2015). Similarly, a bimodal nocturnal pattern of vocal activity has been described in studies of Westland Petrels (Procellaria westlandica; Landers et al. 2011) and 
Yelkouan Shearwaters (Puffinus yelkouan; Bourgeois et al. 2008), with high vocalisation rates in the hours proceeding sunset and the highest in the hours preceding sunrise. Correspondingly, the nightly period of peak vocal activity should be assessed for each study species so as to determine the best period for monitoring throughout breeding seasons and across sites.

\section{Relationship between nesting density and acoustic activity}

The linear regressions fitted to the acoustic index values and density of occupied nest-burrows revealed significant positive relationships in both the incubation and chick-rearing periods. Similarly, in previous work using acoustic data loggers, Oppel et al. (2014) found a positive relationship between calling rate and nest density of Cory's Shearwaters (Calonectris borealis). In the present study the NDSI provided the strongest relationship between vocal activity and occupied nestburrow density at both the new moon and census dates during the incubation and chick-rearing periods. Although the ACI showed a strong relationship in the incubation period, no such relationship was observed for the chick-rearing. Likewise, the ADI showed a strong relationship in the chick-rearing but not during the incubation period, while the AEI and BIO showed none. A potential reason for this may be that these indices are more strongly influenced by other components in the soundscape, such as those occurring in the geophony, or by variation in relative signal intensity and the distance of the vocalisations to the acoustic data logger (e.g. a greater number of birds calling from within their burrow during the incubation period; Sueur et al. 2014). Indeed, in contrast to previous studies e.g. Buxton et al. (2016a) acoustic recordings dominated by wind or rain were not excluded from the dataset in the present study.

The higher variation in the relationship between the NDSI and the density of occupied nest-burrows observed during incubation could be due to the presence of non-breeding adults. Attendance at the colony by non-breeding Short-tailed Shearwaters has been documented in previous studies (Serventy 1967), particularly during the egg-laying and hatching periods, whereas almost no nonbreeders visit colonies during the mid to late chick-rearing period (March). The proportion of nonbreeding adults visiting colonies during the egg-laying/incubation period may vary between sites and years, and is likely to be influenced by local food availability conditions (Klomp and Furness 1990). Some of the observed variation between sites may be due to variation in the proportion of non-breeders present at the breeding colonies; higher density sites may also have a higher 
proportion of non-breeders. During the incubation period, breeding individuals remain on the egg for shifts lasting 9-17 days (Carey 2011) and, hence, any incubating adults would have been counted during the nest censuses carried out during the day. As relatively few non-breeders remain at the colony during the day (Serventy 1967), those attending the colony at night (and contributing to the vocal activity) are unlikely to have been counted in the nest censuses.

In terms of future research, the significant relationships between the NDSI and the density of occupied nest-burrows could provide a valuable tool for predicting occupied nest-burrow density from vocal activity. Used in conjunction with information on the breeding colony area, this could enable estimates of colony population size (Schumann et al. 2013a; Oppel et al. 2014). The regressions could be further validated with a field trial across other Short-tailed Shearwater breeding colonies of varying nest density, comparing the predicted results with observed. Further studies could also establish whether such a predictive relationship could be used to assess hatching success within a given site or year. The relatively low cost of deploying acoustic data loggers suggests this approach could be used to monitor the breeding population of Short-tailed Shearwaters at more numerous locations and at a much higher frequency than currently possible using costly and labour intensive conventional on-the-ground manual nest census surveys. Such information is crucial for the early detection of population trajectory changes at both the regional and species-range scale (Croxall et al. 2012; Paleczny et al. 2015).

The results of the present study suggest temporal and geographic variations in phenology occur, which could provide insights into the ecological processes that influence the species (Wanless et al. 2008). Inter-annual variation in arrival date could be influenced by foraging conditions in the northern hemisphere or winds experienced during the trans-equatorial migration (Baduini et al. 2001b; González-Solís et al. 2009). Geographic and inter-annual differences in the timing of the prelaying exodus could reflect local foraging conditions experienced during the post-migration period, while differences in the duration of the pre-laying exodus could be related to foraging conditions in the Southern Ocean or wind conditions encountered (Raymond et al. 2010). The general decrease in NDSI values during the late chick-rearing period is likely to reflect the decreasing amount of time attending adults spend at the colony during this phase of the breeding season (Einoder 2010) and, thus, could provide an indication of the local foraging conditions (Einoder et al. 2013; Berlincourt and Arnould 2015). Other periodic peaks and variations in NDSI values could reflect weather events impacting recordings (e.g. wind and rain) or reduced vocal 
activity by Short-tailed Shearwaters due to foraging conditions, moonlight exposure or other factors.

In summary, the present study has demonstrated that passive acoustic data logging could feasibly be used as a cost-efficient population monitoring tool for the burrow-nesting Short-tailed Shearwater. If deployed annually, regular estimates of breeding population size could be obtained, enabling the early detection of population trajectory changes. In addition, regular monitoring across the species' range could provide important information on temporal or geographic shifts in phenology. While the present study focused on Short-tailed Shearwaters, and adds to the previous work on seabird species (e.g. Buxton and Jones 2012; Borker et al. 2014; Oppel et al. 2014; Arneill et al. 2019), the method may also be applicable for other burrow- or surface-nesting seabirds for which regular wide-spread monitoring currently proves difficult. In view of current global change and the declining trend of many seabird populations, such tools are essential for the timely detection of population changes and the implementation of appropriate conservation management actions.

\section{Acknowledgements}

We are grateful to the many field assistants who were involved with data collection for this study, in particular, Melanie R. Wells and Timothée Poupart. We thank Parks Victoria for logistical support and are especially grateful to Phil Reichelt, Leo Op Den Brouw, Geoff Sharpe and Tony Symes. We thank Desley Whisson for advice on acoustic data analysis. We also thank the anonymous reviewers for providing helpful comments on the manuscript. The Institut Universitaire de France (IUF) is acknowledged for its support to PB as a Senior Member.

\section{Ethics statement}

Research was conducted following the ethical guidelines of the Deakin University Animal Ethics Committee (Approval B30-2016) under the Department of Environmental, Land, Water and Planning (Victoria, Australia) Wildlife Research Permit \#10008043 and the Department of Primary Industries, Parks, Water and Environment (Tasmania, Australia) Wildlife (General) Regulations 2010 (Regulation 24 and 25) and Threatened Species Protection Regulation 2006 (Regulation 4). 


\section{Funding}

This project was financially supported by research grants from The Holsworth Wildlife Research Endowment and The Ecological Society of Australia, The Winifred Violet Scott Charitable Trust, and Sea World Research \& Rescue Foundation.

\section{References}

Arneill, G. E., Critchley, E. J., Wischnewski, S., Jessopp, M. J., and Quinn, J. L. (2019). Acoustic activity across a seabird colony reflects patterns of within-colony flight rather than nest density. Ibis. 162(2): 416-428.

Baduini, C. L., Hyrenbach, K. D., Coyle, K. O., Pinchuk, A., Mendenhall, V., and Hunt, G. L., Jr. (2001a). Mass mortality of Short-tailed Shearwaters in the South-Eastern Bering Sea during summer 1997. Fisheries Oceanography 10:1, 117-130.

Baduini, C. L., Lovvorn, J. R., and Hunt, G. L. (2001b). Determining the body condition of Shorttailed Shearwaters: Implications for migratory flight ranges and starvation events. Marine Ecology Progress Series 222, 265-277.

Berlincourt, M., and Arnould, J. P. Y. (2015). Breeding Short-tailed Shearwaters buffer local environmental variability in south-eastern Australia by foraging in Antarctic waters. Movement Ecology 3(1), 16.

Boelman, N. T., Asner, G. P., Hart, P. J., and Martin, R. E. (2007). Multi-trophic invasion resistance in Hawaii: Bioacoustics, field surveys, and airborne remote sensing. Ecological Applications 17(8), 2137-2144.

Borker, A. L., Buxton, R. T., Jones, I. L., Major, H. L., Williams, J. C., Tershy, B. R., and Croll, D. A. (2020). Do soundscape indices predict landscape-scale restoration outcomes? A comparative study of restored seabird island soundscapes. Restoration Ecology 28, 252-260.

Borker, A. L., McKown, M. W., Ackerman, J. T., Eagles-Smith, C. A., Tershy, B. R., and Croll, D. A. (2014). Vocal activity as a low cost and scalable index of seabird colony size. Conservation Biology 28(4), 1100-1108. 
Bourgeois, K., Dromzée, S., Vidal, É., and Legrand, J. (2008). Yelkouan shearwater Puffinus yelkouan presence and behaviour at colonies: Not only a moonlight question. Comptes Rendus Biologies 331(1), 88-97.

Brisson-Curadeau, É., Bird, D., Burke, C., Fifield, D. A., Pace, P., Sherley, R. B., and Elliott, K. H. (2017). Seabird species vary in behavioural response to drone census. Scientific Reports 7(1), 17884.

Buxton, R. T., Brown, E., Sharman, L., Gabriele, C. M., and McKenna, M. F. (2016a). Using bioacoustics to examine shifts in songbird phenology. Ecology and Evolution 6(14), 4697-4710.

Buxton, R. T., Gormley, A. M., Jones, C. J., and Lyver, P. O. B. (2016b). Monitoring burrowing petrel populations: A sampling scheme for the management of an island keystone species. The Journal of Wildlife Management 80(1), 149-161.

Buxton, R. T., and Jones, I. L. (2012). Measuring nocturnal seabird activity and status using acoustic recording devices: Applications for island restoration. Journal of Field Ornithology 83(1), 47-60.

Buxton, R. T., McKenna, M. F., Clapp, M., Meyer, E., Stabenau, E., Angeloni, L. M., Crooks, K., et al. (2018). Efficacy of extracting indices from large-scale acoustic recordings to monitor biodiversity. Conservation Biology 32(5), 1174-1184.

Cai, W., Shi, G., Cowan, T., Bi, D., and Ribbe, J. (2005). The response of the Southern Annular Mode, the East Australian Current, and the southern mid-latitude ocean circulation to global warming. Geophysical Research Letters 32, L23706.

Carey, M. J. (2011). Incubation routine, duration of foraging trips and regulation of body mass in Short-tailed Shearwaters (Ardenna tenuirostris). Emu - Austral Ornithology 111(2), 166-171.

Comiso, J. C., Parkinson, C. L., Gersten, R., and Stock, L. (2008). Accelerated decline in the Arctic sea ice cover. Geophysical Research Letters 35, L01703.

Cragg, J. L., Burger, A. E., and Piatt, J. F. (2015). Testing the effectiveness of automated acoustic sensors for monitoring vocal activity of Marbled Murrelets Brachyramphus marmoratus. Marine Ornithology 43, 151-160.

Croxall, J. P., Butchart, S. H. M., Lascelles, B. E. N., Stattersfield, A. J., Sullivan, B. E. N., Symes, A., and Taylor, P. (2012). Seabird conservation status, threats and priority actions: A global assessment. Bird Conservation International 22(01), 1-34. 
Einoder, L. D. (2010). The foraging ecology of the short-tailed Shearwater Puffinus tenuirostris. Ph.D. Thesis, Adelaide University, Adelaide, Australia

Einoder, L. D., Page, B., and Goldsworthy, S. D. (2013). Feeding strategies of the Short-tailed Shearwater vary by year and sea-surface temperature but do not affect breeding success. The Condor 115(4), 777-787.

Fretwell, P. T., Scofield, P., and Phillips, R. A. (2017). Using super-high resolution satellite imagery to census threatened albatrosses. Ibis 159(3), 481-490.

Fuller, S., Axel, A. C., Tucker, D., and Gage, S. H. (2015). Connecting soundscape to landscape: Which acoustic index best describes landscape configuration? Ecological Indicators 58, 207215.

Gall, A. E., Morgan, T. C., Day, R. H., and Kuletz, K. J. (2017). Ecological shift from piscivorous to planktivorous seabirds in the Chukchi Sea, 1975-2012. Polar Biology 40(1), 61-78.

Gini, C. (1912). Variabilità e mutabilità. In 'Memorie di Metodologica Statistica.' (Eds E. Pizetti and T. Salvemini.) pp. 211-382. (Liberia Eredi Virgilio Veschi: Rome, Italy.)

González-Solís, J., Felicísimo, A., Fox, J. W., Afanasyev, V., Kolbeinsson, Y., and Muñoz, J. (2009). Influence of sea surface winds on shearwater migration detours. Marine Ecology Progress Series 391, 221-230.

Kasten, E. P., Gage, S. H., Fox, J., and Joo, W. (2012). The remote environmental assessment laboratory's acoustic library: An archive for studying soundscape ecology. Ecological Informatics 12, 50-67.

Klomp, N. I., and Furness, R. W. (1990). Variations in numbers of nonbreeding Great Skuas attending a colony. Ornis Scandinavica (Scandinavian Journal of Ornithology) 21(4), 270-276.

Landers, T. J., Bannock, C. A., and Hauber, M. E. (2011). Dynamics of behavioural rhythms in a colonial, nocturnal, burrowing seabird: A comparison across different temporal scales. Notornis $58(2), 81-89$.

Last, P. R., White, W. T., Gledhill, D. C., Hobday, A. J., Brown, R., Edgar, G. J., and Pecl, G. (2011). Long-term shifts in abundance and distribution of a temperate fish fauna: A response to climate change and fishing practices. Global Ecology and Biogeography 20(1), 58-72.

Ligges, U., Krey, S., Mersmann, O., and Schnackenberg, S. (2018). tuneR: Analysis of music and speech. Available at https://cran.rproject.org/web/packages/tuneR/citation.html [Verified 7 February 2019]. 
Lough, J. M., and Hobday, A. J. (2011). Observed climate change in Australian marine and freshwater environments. Marine and Freshwater Research 62(9), 984-999.

Marchant, S. A., and Higgins, P. J. (1990). 'Handbook of Australian, New Zealand and Antarctic Birds.' (Oxford University Press: Melbourne.)

Marques, T. A., Thomas, L., Martin, S. W., Mellinger, D. K., Ward, J. A., Moretti, D. J., Harris, D., et al. (2013). Estimating animal population density using passive acoustics. Biological Reviews 88(2), 287-309.

Mougeot, F., and Bretagnolle, V. (2000). Predation risk and moonlight avoidance in nocturnal seabirds. Journal of Avian Biology 31, 376-386.

Oppel, S., Hervias, S., Oliveira, N., Pipa, T., Silva, C., Geraldes, P., Goh, M., et al. (2014). Estimating population size of a nocturnal burrow-nesting seabird using acoustic monitoring and habitat mapping. Nature Conservation 7, 1-13.

Otero, X. L., De La Peña-Lastra, S., Pérez-Alberti, A., Ferreira, T. O., and Huerta-Diaz, M. A. (2018). Seabird colonies as important global drivers in the nitrogen and phosphorus cycles. Nature Communications 9(1), 246.

Paleczny, M., Hammill, E., Karpouzi, V., and Pauly, D. (2015). Population trend of the world's monitored seabirds, 1950-2010. Plos One 10(6), e0129342.

Parker, G. C., and Rexer-Huber, K. (2016). Guidelines for designing burrowing petrel surveys to improve population estimate precision. Agreement on the conservation of Albatrosses and Petrels. Available at http://www.acap.aq/en/resources/acap-conservation-guidelines [Verified 7 February 2019].

Pieretti, N., Farina, A., and Morri, D. (2011). A new methodology to infer the singing activity of an avian community: The Acoustic Complexity Index (ACI). Ecological Indicators 11(3), 868873.

Pijanowski, B. C., Villanueva-Rivera, L. J., Dumyahn, S. L., Farina, A., Krause, B. L., Napoletano, B. M., Gage, S. H., et al. (2011). Soundscape ecology: The science of sound in the landscape. BioScience 61(3), 203-216.

Precheur, C., Barbraud, C., Martail, F., Mian, M., Nicolas, J.-C., Brithmer, R., Belfan, D., et al. (2016). Some like it hot: Effect of environment on population dynamics of a small tropical seabird in the Caribbean region. Ecosphere 7(10), e01461. 
R Core Team (2019). R: A language and environment for statistical computing. R Foundation for Statistical Computing, Vienna, Austria.

Raymond, B., Shaffer, S. A., Sokolov, S., Woehler, E. J., Costa, D. P., Einoder, L., Hindell, M., et al. (2010). Shearwater foraging in the Southern Ocean: The roles of prey availability and winds. PLoS One 5(6), e10960.

Rubolini, D., Maggini, I., Ambrosini, R., Imperio, S., Paiva, V. H., Gaibani, G., Saino, N., et al. (2015). The effect of moonlight on Scopoli's Shearwater Calonectris diomedea colony attendance patterns and nocturnal foraging: A test of the foraging efficiency hypothesis. Ethology 121(3), 284-299.

Schofield, O., Ducklow, H. W., Martinson, D. G., Meredith, M. P., Moline, M. A., and Fraser, W. R. (2010). How do polar marine ecosystems respond to rapid climate change? Science 328(5985), 1520.

Schreiber, E. A., and Burger, J. (2002). 'Biology of Marine Birds.' (CRC Press: Boca Raton, USA.) Schumann, N. (2012). Niche separation in burrowing seabirds of Bass Strait. Ph.D. Thesis, Deakin University, Melbourne, Australia.

Schumann, N., Dann, P., and Arnould, J. P. Y. (2013a). Use of terrestrial habitats by burrownesting seabirds in south-eastern Australia. Emu - Austral Ornithology 113(2), 135-144.

Schumann, N., Dann, P., and Arnould, J. P. Y. (2014). The significance of northern-central Bass Strait in south-eastern Australia as habitat for burrowing seabirds. Emu - Austral Ornithology 114(3), 234-240.

Schumann, N., Dann, P., Hoskins, A. J., and Arnould, J. P. Y. (2013b). Optimizing survey effort for burrow-nesting seabirds. Journal of Field Ornithology 84(1), 69-85.

Serventy, D. L. (1967). Aspects of the population ecology of the Short-tailed Shearwater Puffinus tenuirostris. In 'Proceedings of the 14th International Ornithological Congress, '. pp. 165-190. 24-30 July 1966. (Oxford, United Kingdom).

Shannon, C. E., and Weaver, W. (1949). 'The Mathematical Theory of Communication.' (University of Illinois Press: Urbana.)

Skira, I. J., Brothers, N. P., and Pemberton, D. (1996). Distribution, abundance and conservation status of Short-tailed Shearwaters Puffinus tenuirostris in Tasmania, Australia. Marine Ornithology 24, 1-14. 
Sueur, J., Farina, A., Gasc, A., Pieretti, N., and Pavoine, S. (2014). Acoustic indices for biodiversity assessment and landscape investigation. Acta Acustica United Acustica 100(4), 772-781.

Towsey, M., Wimmer, J., Williamson, I., and Roe, P. (2014). The use of acoustic indices to determine avian species richness in audio-recordings of the environment. Ecological Informatics $21,110-119$.

Vertigan, C. (2010). The life-history of Short-tailed Shearwaters (Puffinus tenuirostris) in response to spatio-temporal environmental variation. Ph.D. Thesis, University of Tasmania, Hobart, Australia.

Villanueva-Rivera, L. J., and Pijanowski, B. C. (2016). Soundecology: Soundscape Ecology. R package version 1.3.2. Available at https://CRAN.R-project.org/package=soundecology [Verified 7 March 2019].

Villanueva-Rivera, L. J., Pijanowski, B. C., Doucette, J., and Pekin, B. (2011). A primer of acoustic analysis for landscape ecologists. Landscape Ecology 26(9), 1233.

Wanless, S., Harris, M. P., Lewis, S., Frederiksen, M., and Murray, S. (2008). Later breeding in northern gannets in the eastern Atlantic. Marine Ecology Progress Series 370, 263-269.

Wernberg, T., Russell, B. D., Moore, P. J., Ling, S. D., Smale, D. A., Campbell, A., Coleman, M. A., et al. (2011). Impacts of climate change in a global hotspot for temperate marine biodiversity and ocean warming. Journal of Experimental Marine Biology and Ecology 400(1), 7-16.

Wood, S. N. (2004). Stable and efficient multiple smoothing parameter estimation for generalized additive models. Journal of the American Statistical Association 99(467), 673-686.

Yamamoto, T., Hoshina, K., Nishizawa, B., Meathrel, C. E., Phillips, R. A., and Watanuki, Y. (2014). Annual and seasonal movements of migrating Short-tailed Shearwaters reflect environmental variation in sub-Arctic and Arctic waters. Marine Biology 162(2), 413-424. 
Table 1. Density of nest-burrows (including occupied, unoccupied and unknown status burrows) and density of occupied nest-burrows within a $10 \mathrm{~m}$ radius of the acoustic data loggers across the Short-tailed Shearwater study sites in 2016/17 and 2017/18.

\begin{tabular}{|c|c|c|c|c|c|c|c|c|c|c|c|c|c|}
\hline \multirow[b]{3}{*}{ Site } & \multirow[b]{3}{*}{ Census method } & \multicolumn{6}{|c|}{$2016 / 17$} & \multicolumn{6}{|c|}{$2017 / 18$} \\
\hline & & \multicolumn{3}{|c|}{ Incubation } & \multicolumn{3}{|c|}{ Chick-rearing } & \multicolumn{3}{|c|}{ Incubation } & \multicolumn{3}{|c|}{ Chick-rearing } \\
\hline & & Date & $\mathrm{ND} \cdot \mathrm{m}^{-2}$ & $\mathrm{OD} \cdot \mathrm{m}^{-2}$ & Date & $\mathrm{ND} \cdot \mathrm{m}^{-2}$ & $\mathrm{OD} \cdot \mathrm{m}^{-2}$ & Date & $\mathrm{ND} \cdot \mathrm{m}^{-2}$ & OD.m $\mathrm{m}^{-2}$ & Date & $\mathrm{ND} \cdot \mathrm{m}^{-2}$ & OD $\cdot \mathrm{m}^{-2}$ \\
\hline Kanowna Island 1 & Manual inspection & $12 \mathrm{Dec}$ & 1.20 & 0.66 & $10 \mathrm{Mar}$ & 0.87 & 0.24 & $6 \mathrm{Dec}$ & 1.11 & 0.70 & $8 \mathrm{Mar}$ & 1.18 & 0.46 \\
\hline Kanowna Island 2 & Manual inspection & $13 \mathrm{Dec}$ & 0.83 & 0.28 & $11 \mathrm{Mar}$ & 0.60 & 0.07 & $8 \mathrm{Dec}$ & 0.94 & 0.43 & $8 \mathrm{Mar}$ & 0.91 & 0.25 \\
\hline Gabo Island 1 & Burrowscope & $11 \mathrm{Dec}$ & 0.24 & 0.11 & $8 \mathrm{Mar}$ & 0.24 & 0.00 & $7 \mathrm{Dec}$ & 0.22 & 0.12 & $12 \mathrm{Mar}$ & 0.22 & 0.05 \\
\hline Gabo Island 2 & Burrowscope & $13 \mathrm{Dec}$ & 0.39 & 0.24 & $10 \mathrm{Mar}$ & 0.40 & 0.15 & $4 \mathrm{Dec}$ & 0.39 & 0.28 & $14 \mathrm{Mar}$ & 0.41 & 0.22 \\
\hline Point Danger & Burrowscope & $17 \mathrm{Dec}$ & 0.02 & 0.00 & - & - & - & $18 \mathrm{Dec}$ & 0.01 & 0.00 & - & - & - \\
\hline Fort Direction & Grubbing & $6 \mathrm{Dec}$ & 0.55 & 0.34 & $7 \mathrm{Mar}$ & 0.61 & 0.11 & $15 \mathrm{Dec}$ & 0.73 & 0.33 & $15 \mathrm{Mar}$ & 0.65 & 0.17 \\
\hline Whalebone Point & Grubbing & $7 \mathrm{Dec}$ & 0.53 & 0.41 & $9 \mathrm{Mar}$ & 0.53 & 0.23 & $12 \mathrm{Dec}$ & 0.52 & 0.37 & $20 \mathrm{Mar}$ & 0.37 & 0.11 \\
\hline Cloudy Bay & Grubbing & - & - & - & - & - & - & $12 \mathrm{Dec}$ & 0.60 & 0.32 & $29 \mathrm{Mar}$ & 0.52 & 0.08 \\
\hline
\end{tabular}

ND: Nest density (burrows $\cdot \mathrm{m}^{-2}$ )

OD: Occupied nest density (burrows $\cdot \mathrm{m}^{-2}$ ) 
Table 2. Linear regressions between the mean new moon acoustic index values (normalised difference soundscape index (NDSI), acoustic complexity index (ACI), acoustic diversity index (ADI), acoustic evenness index (AEI), and bioacoustic index (BIO)) and the density of occupied nest-burrows during the incubation $(n=14)$ and chick-rearing periods $(n=10)$ for all Short-tailed Shearwater study sites over the breeding seasons 2016/2017 and 2017/2018.

\begin{tabular}{|c|c|c|c|c|c|c|c|c|c|c|c|c|c|c|}
\hline \multirow[b]{2}{*}{ Acoustic index } & \multicolumn{7}{|c|}{ Incubation } & \multicolumn{7}{|c|}{ Chick-rearing } \\
\hline & Intercept & SE & Slope & SE & $F_{(1,12)}$ & $P$-value & $r^{2}$ & Intercept & SE & Slope & SE & $F_{(1,8)}$ & $P$-value & $r^{2}$ \\
\hline NDSI & 0.207 & 0.043 & 0.462 & 0.108 & 18.21 & 0.001 & 0.60 & 0.155 & 0.015 & 0.486 & 0.060 & 63.73 & 0.000 & 0.89 \\
\hline $\mathrm{ACl}$ & -5.268 & 1.203 & 0.003 & 0.0006 & 21.45 & 0.001 & 0.64 & -0.385 & 1.014 & 0.0003 & 0.0005 & 0.30 & 0.599 & 0.04 \\
\hline ADI & -1.624 & 1.102 & 0.906 & 0.517 & 3.07 & 0.105 & 0.20 & -0.560 & 0.314 & 0.412 & 0.176 & 5.47 & 0.048 & 0.41 \\
\hline $\mathrm{AEI}$ & 0.549 & 0.197 & -0.938 & 0.722 & 1.69 & 0.218 & 0.12 & 0.470 & 0.168 & -0.636 & 0.347 & 3.36 & 0.104 & 0.30 \\
\hline $\mathrm{BIO}$ & -0.411 & 0.348 & 0.074 & 0.036 & 4.29 & 0.061 & 0.26 & 0.316 & 0.235 & -0.015 & 0.024 & 0.40 & 0.543 & 0.05 \\
\hline
\end{tabular}

Significant results are indicated in bold $(\mathrm{P}<0.05)$.

SE: Standard error. 

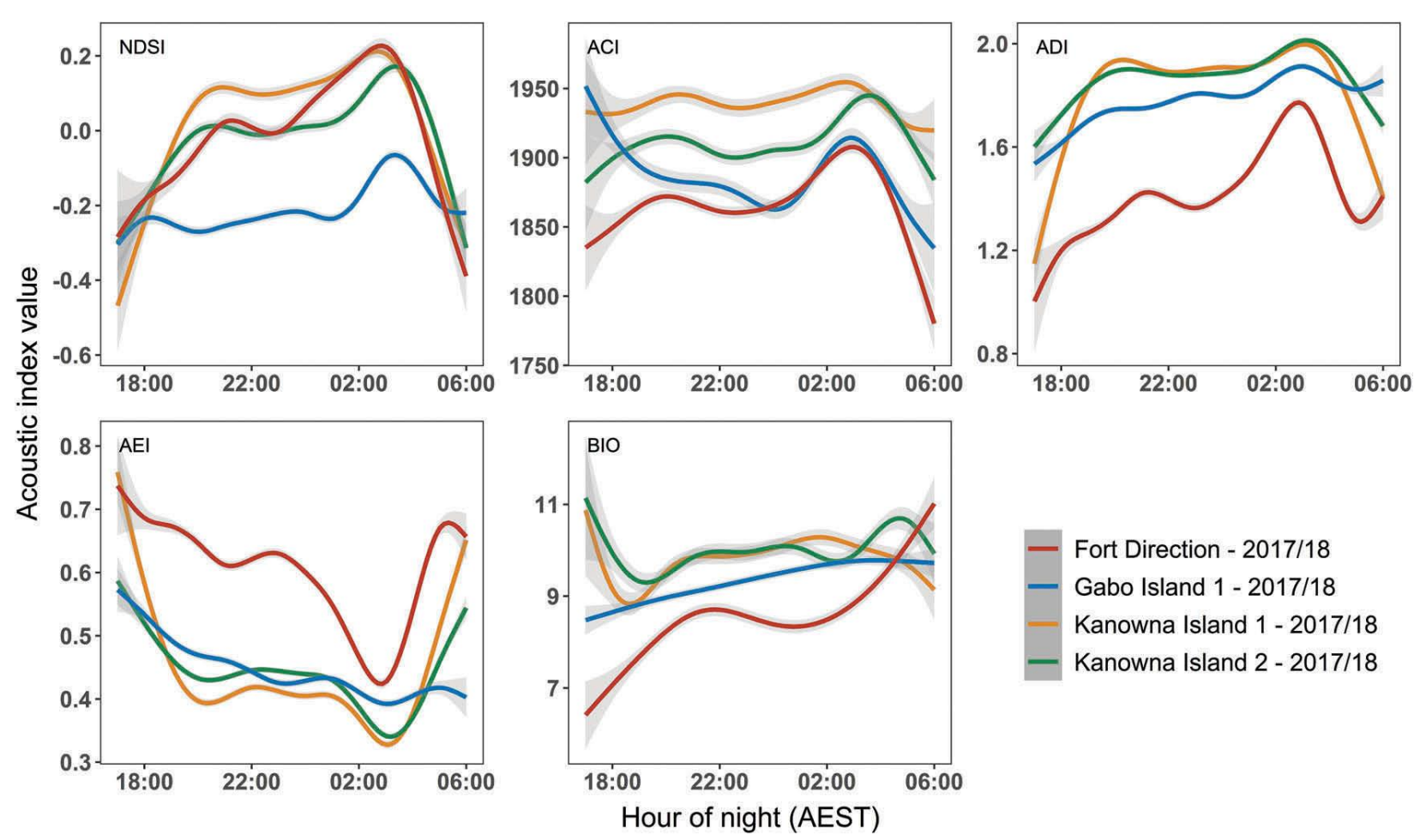

Fort Direction - 2017/18

Gabo Island 1 - 2017/18

Kanowna Island 1 - 2017/18

Kanowna Island 2 - 2017/18

Figure 1. Nightly temporal variation in the hourly (Australian Eastern Standard Time, AEST) acoustic indices values for the entire breeding season, with values and standard errors (grey shaded area) predicted from Generalised Additive Models (GAMs) for four Short-tailed Shearwater colonies study sites during the 2017/2018 breeding season. Acoustic indices shown are the normalised difference soundscape index (NDSI), acoustic complexity index (ACI), acoustic diversity index (ADI), acoustic evenness index (AEI), and bioacoustic index (BIO). Other sites and years showed similar patterns. 


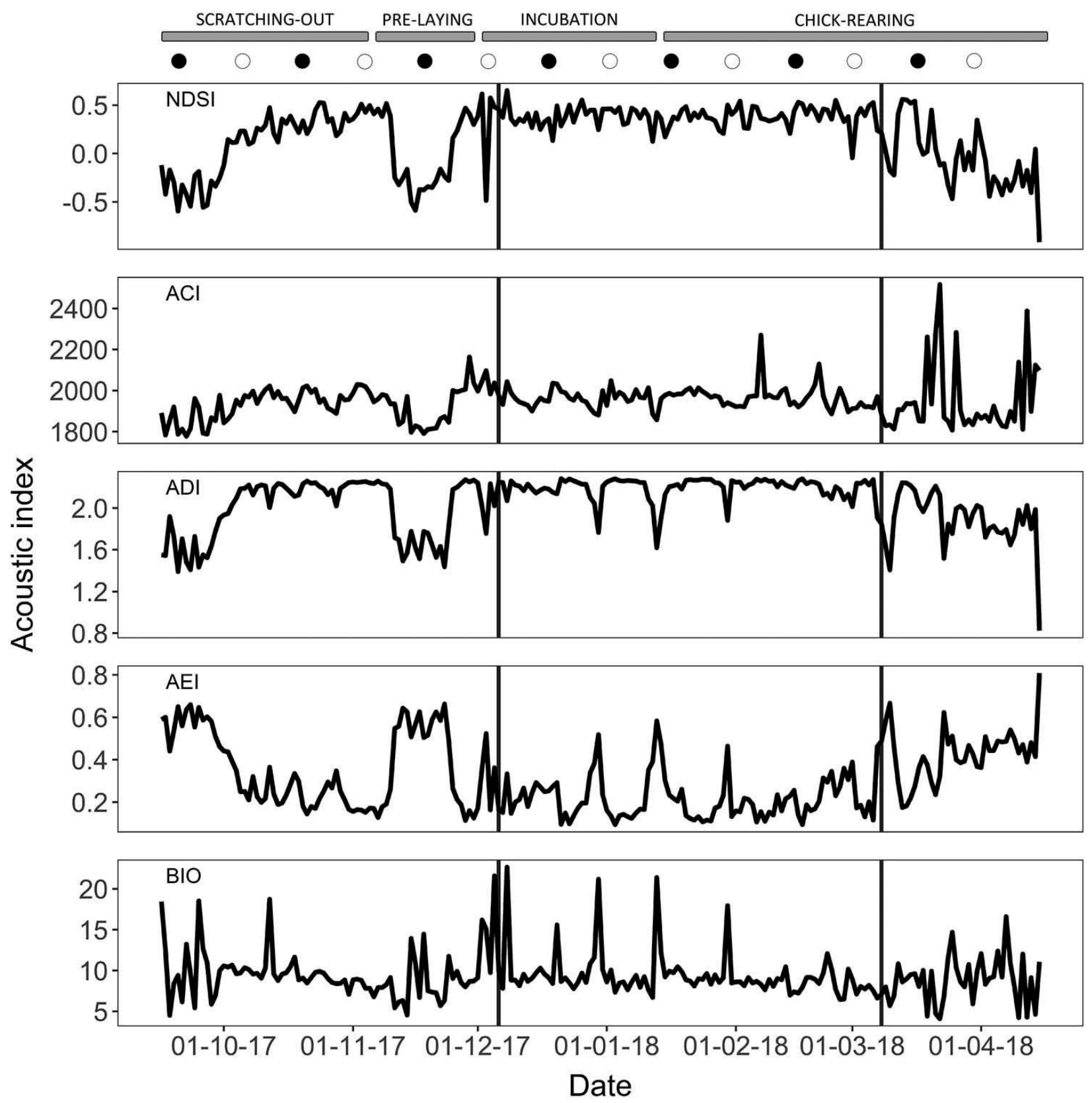

Figure 2. A representative comparison of the different acoustic indices values (normalised difference soundscape index (NDSI), acoustic complexity index (ACI), acoustic diversity index (ADI), acoustic evenness index (AEI), and bioacoustic index (BIO)) at a Shorttailed Shearwater colony (Kanowna Island Site 2) during an entire breeding season (2017/2018). The moon phases are indicated by solid (new moon) and open circles (full moon), the major phenology events by grey bars, and the solid lines indicate the nest census dates. Other sites and years showed similar patterns. 


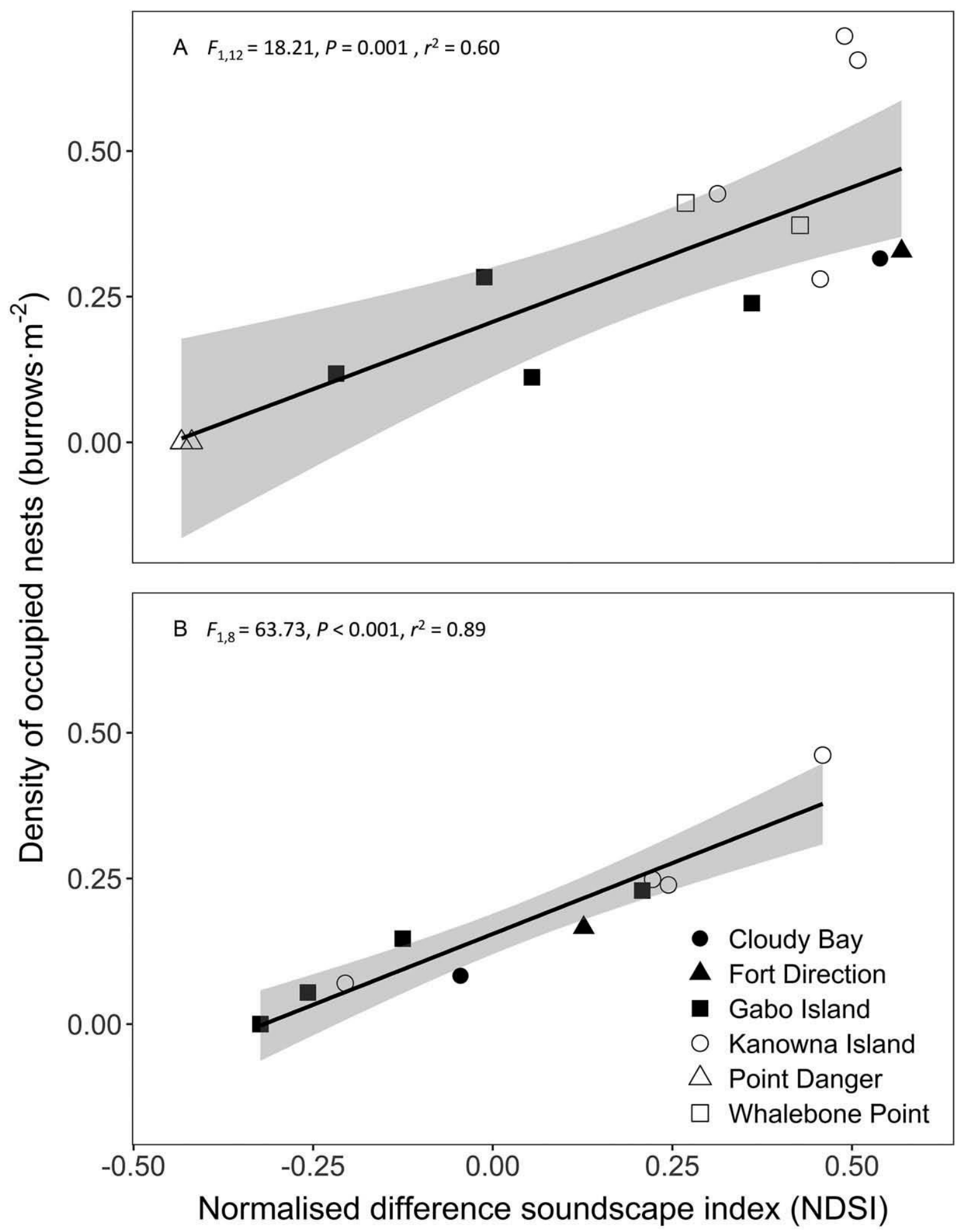

Figure 3. Density of occupied nests (burrows $\mathrm{m}^{-2}$ ) at all Short-tailed Shearwater study sites with available data and averaged five day new moon normalised difference soundscape index (NDSI) values for the (a) incubation period 2016 and 2017 ( $n=14)$ and (b) chick-rearing period 2017 and $2018(\mathrm{n}=10$, linear regression and 95\% confidence intervals). 